\title{
Responses to a poached conspecific in wild forest elephants (Loxodonta africana cyclotis)
}

\author{
Claudia Stephan $^{\mathrm{a}, \mathrm{b}, *}$, Jess J.D. Bahamboula ${ }^{\mathrm{b}}$ and Terry M. Brncic ${ }^{\mathrm{a}, \mathrm{b}}$ \\ ${ }^{\text {a }}$ Wildlife Conservation Society - Congo Program, PO Box 14537, Brazzaville, \\ Republic of Congo \\ ${ }^{\mathrm{b}}$ Nouabalé-Ndoki Foundation, PO Box 14537, Brazzaville, Republic of Congo \\ *Corresponding author's e-mail address: cl.stephan@outlook.com
}

Received 3 October 2019; initial decision 4 November 2019; revised 27 June 2020; accepted 25 July 2020; published online 31 August 2020

\begin{abstract}
The increased attention towards deceased conspecifics in various social animal species is one of the most intriguing conundrums in animal behaviour. The factors that might explain the observed behavioural variation amongst individuals remain nebulous. Here we analyse forest elephants' (Loxodonta africana cyclotis) responses to a poached adult male conspecific, using remote camera trapping during a period of eight months. After completely avoiding the carcass site for over a week, females and males substantially differed in behavioural responses. Males consistently stayed longer around the remains, showed signs of increased arousal, interacted with the dead body, and twisted trunks with each other. Females, in contrast, were more passively explorative and preferred to visit the site without their dependent offspring. Findings show a previously unknown sexual-dimorphism in forest elephant behaviour towards a poached conspecific and raise the possibility that individuals might be able to infer further context-specific information about the event.
\end{abstract}

\section{Keywords}

forest elephants, comparative thanatology, poaching, camera traps.

\section{Introduction}

Comparative thanatology, the study of others' responses to dying and dead conspecifics, has received increasing attention within the past years (Berkovitch, 2019), especially as it still remains unclear if there are any nonhuman animal precursors to the 'culturalised' death in humans (Huntington 
$\&$ Metcalf, 1979; Shimane, 2018). Species facing the necessity to manoeuvre short-term social relationships in fission-fusion systems seem to show particular interest in dead conspecifics (chimpanzees, Pan troglodytes: Stewart et al., 2012; savannah elephants, Loxodonta africana africana: DouglasHamilton et al., 2006; cetaceans: Bearzi et al., 2018), most likely to update social information (Anderson, 2016). For instance, savannah elephants, who depend on social information transfer and who possess many differentiated social relationships throughout life (McComb et al., 2001; Foley, 2002), have been repeatedly reported to approach, investigate and to touch deceased conspecifics, even when they have not previously been closely bonded to them (Goldenberg \& Wittemyer, 2019).

Like savannah elephants, forest elephants (Loxodonta africana cyclotis) live in social systems that are driven by fission-fusion dynamics (Turkalo \& Fay, 2001; Wittemyer et al., 2005; Fishlock \& Lee, 2013; Breuer \& Fishlock, 2015), which are characterised by high degrees of spatial and temporal variability of social aggregations. Unlike in savannah elephants, social core units are usually small in forest elephants (2 to 4 individuals, White et al., 1993). Females are most likely organized in units of kin and affiliates that are temporally more flexible than in savannah elephants (Turkalo \& Fay, 1995; Wittemyer et al., 2005; Mbeli Baï Study, unpublished data). Male forest elephants follow more linear dominance hierarchies and do not form bachelor aggregations like seen in savannah elephants (Turkalo \& Fay, 1995; Fishlock et al., 2008; Chiyo et al., 2011; Mbeli Baï Study, unpublished data). Due to the difficulty of systematically observing and following individuals in dense forest habitats, detailed insights into forest elephants' social lives and in similarities and differences with savannah elephants remain scarce, including responses to death.

After more than 20 years without any poaching incident around the forest clearing Mbeli Baï, an approximately 45-year-old male forest elephant was killed the 24th September 2017 at about 16:00, approximately $150 \mathrm{~m}$ from the clearing. The male was known to the Mbeli Baï Study since 1997. Poachers removed both ears and the tail, cut out the heart and removed both tusks. We report here on behavioural responses from individually identified forest elephants that were recorded next to this poached conspecific for the duration of 6 months. 


\section{Methods}

\subsection{Study site and population}

The study was conducted in the mono-dominant Gilbertiodendron dewevrei forest surrounding Mbeli Baï, a 12.9 ha natural forest clearing that is permanently covered by floating aquatic vegetation, in the Nouabalé-Ndoki National Park, Republic of Congo $\left(2^{\circ} 15.50 \mathrm{~N}, 16^{\circ} 24.70 \mathrm{E}\right.$; altitude about $300 \mathrm{~m}$ ). The Mbeli Baï Study observes forest elephants who visit the Baï mainly to complement their diet with mineral rich soil and vegetation (Klaus et al., 1998; Blake, 2002; Sienne et al., 2014), and who probably use the open foraging space to establish and maintain social relationships (Fishlock \& Lee, 2013). Individual identification of forest elephants began in 1995, using individual features like ear-vein patterns, form and size of tusks, and tail hair. Sex and age were determined following established measures in forest elephant research (infants, Inf: 0.1-4 years, juveniles, Juv: 4.1-8 years, subadults, Sa (F or M): 8.1-15 years, young adult males, Yam: 15.1-25 years, adult females, Af: $>15$ years, adult males, Am: $>25$ years; Fishlock, 2010; Turkalo, 2013). The long-term demographic database currently includes almost 600 known individuals.

\subsection{Data collection and analysis}

From 26 September 2017 until 10 March 2018, we placed a Bushnell HD camera trap that automatically took motion-triggered, still-pictures next to the carcass, covering a viewing area of about $10 \mathrm{~m}^{2}$. The carcass was located just next to an elephant trail, which is normally frequently used by elephants (as indicated by minimal vegetation on the trail, compressed soil and lowered level in comparison to surrounding forest floor). Individuals that were identified from the camera trap pictures are reported for the number of visits they made to the carcass during the study period, the duration that they stayed at the site, and the behaviour that they performed. To quantify behaviour, all behaviours observed during individual visits were coded (Table 1) and their duration measured using time stamps on the first and the last picture showing the respective behaviour. To control for different durations of visits per individual, percentages of time spent for specific behaviours were calculated for each individual by taking a behaviour's duration multiplied by 100 and divided by the duration of the entire recorded visit. We report the mean proportion of time spent for observed behaviours for adult individuals during first visits at the carcass. Repeated sightings of an individual during the 
Table 1.

Ethogram of behavioural variables that were coded from images.

\begin{tabular}{ll}
\hline Variable & Explanation \\
\hline Interaction carcass & $\begin{array}{l}\text { touching and/or displacing bones with feet, tusks or trunk } \\
\text { breaking branches and removing vegetation with tusks or trunk } \\
\text { Interaction vegetation } \\
\text { orienting trunk straight and directly towards carcass } \\
\text { orienting trunk straight and directly towards camera } \\
\text { Trunk camera }\end{array}$ \\
touching and entwining another individual's trunk \\
Looking carcass & $\begin{array}{l}\text { head position and looking direction towards carcass } \\
\text { head position and looking direction towards camera }\end{array}$ \\
\hline
\end{tabular}

same day that were separated by at least an hour and sightings on different days were counted as different visits. Changes in visit numbers over time after the poaching event were analysed using Spearman's rank coefficients by means of the cor.test function of the "stats" package and plotted using the plot function of the "graphics" package (R v. 3.6.1, R Core Team, 2019).

\section{Results}

During 182 days, 193 visits were recorded, of which 140 were made by 59 different identified individuals (Table 1). Ninety-four\% of identified visits occurred between 16:30 and 06:30, which is in line with previous reports of elephant activity patterns (Fishlock, 2010; Gessner et al., 2013). Despite normally frequent use of the adjacent trail, no elephant was recorded at the carcass site during the first 8 days after the poaching event. After this, elephants were recorded alone or in groups composed of 2-7 individuals (median: 1) and the number of visits continuously increased with time after the poaching event (Spearman's rank coefficients: rho $=0.79, S=373.29$, $p<0.0001$; Figure 1). Adult males and young adult males stayed longer close to the carcass during first visits than other age classes (median 7 and 9.5 min, respectively). Both adult males and adult females were observed to repeatedly visit the dead body, although inter-individual variability was considerable. For instance, the majority of females (10 of 14) only visited the carcass twice, but one female returned 9 times to the dead body and stayed on average $10 \mathrm{~min} /$ visit (Table 2). Similarly, the adult male who visited the carcass most (8 times), also accounted for the three longest visits $(58,47$ and $39 \mathrm{~min}$ ). For first visits, adult females mostly showed exploratory behaviour without directly interacting like looking at the carcass (39\% of time 


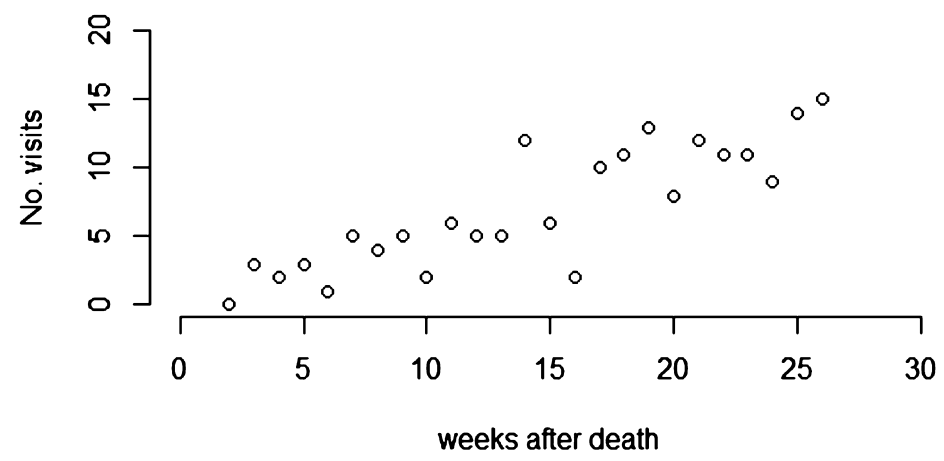

Figure 1. The number of elephant visits per week at the carcass site with increasing time after the poaching events.

spent within camera range) or directing their trunk towards it (53\%). In contrast, adult and young adult males predominantly interacted physically with the dead body (57 and 32\%, respectively) or the surrounding vegetation (33 and $45 \%$, respectively; Figure 2). More rarely, adult individuals were captured looking in the direction of the camera or directing their trunk towards the camera (adult females $8 \%$, adult males $8 \%$, young adult males 22\%). On two occasions, males were recorded to twist their trunks (adult males $2 \%$, young adult males $1 \%$ of time during first visits). Younger age classes performed behaviour similar to those of adult females. Generally, individuals did not considerably change their behaviour between first and subsequent visits, although adult females tended to interact more with the vegetation during second visits. Of the 14 identified adult females, 11 were known to have dependent offspring. Although these females were usually observed visiting the nearby Bai with their infants during the study period (Mbeli Bai Study, long-term data), they were only recorded with their infants at the carcass site during 6 out of 23 visits made from October 2017 until March 2018, and only starting in January 2018, 3 months after the poaching event.

\section{Discussion}

The present observations revealed several similarities and differences to previous reports for elephants' responses to dead conspecifics. As observed in savannah elephants, forest elephants showed high interest in even the bones of the deceased adult male. Furthermore, behaviours observed here are in line with savannah elephant behaviour towards dead conspecifics like approaching, touching and investigating the dead body (Goldenberg \& Wittemyer, 

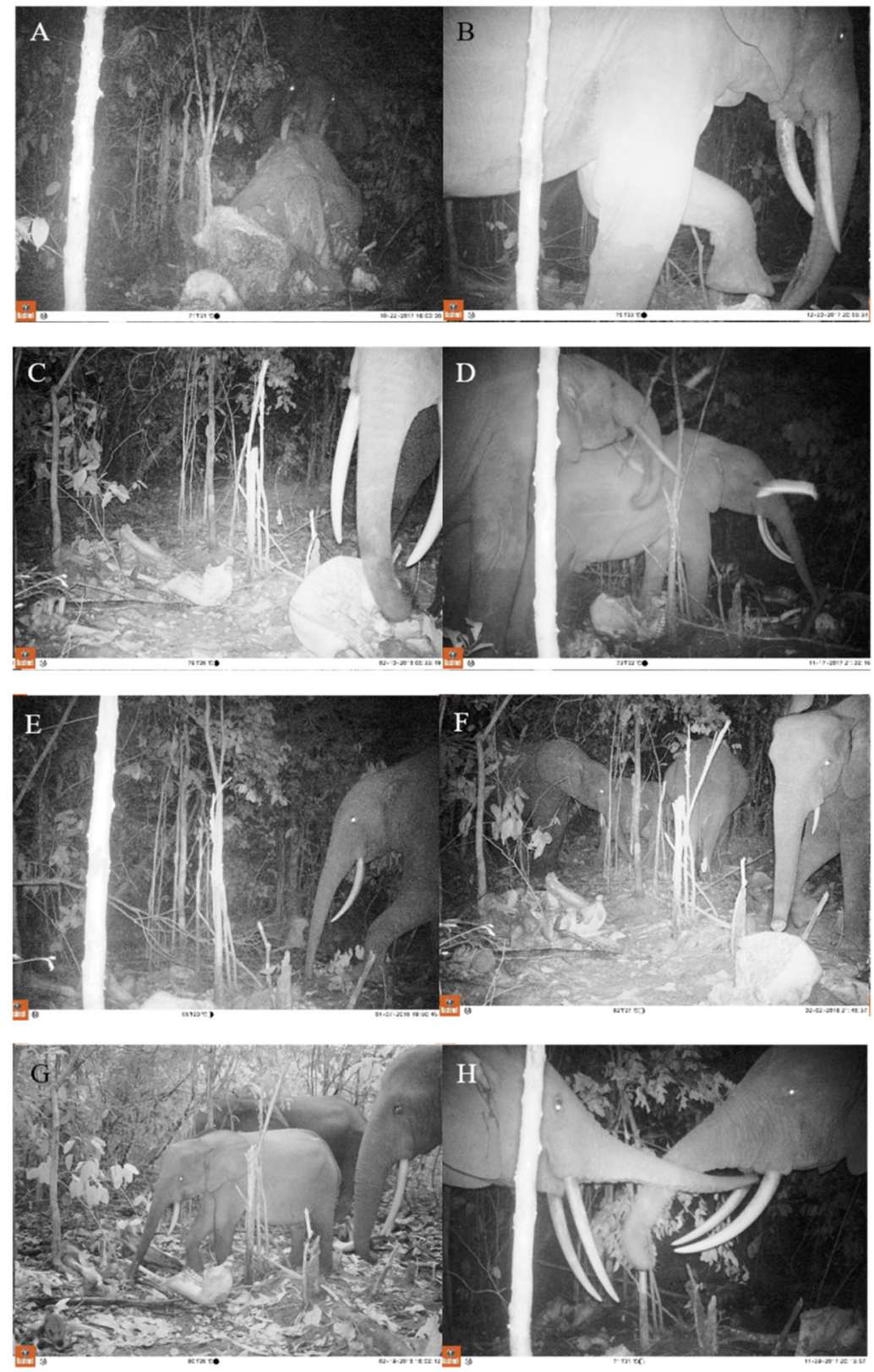

Figure 2. Frequently observed elephant behaviour at the carcass site: $(A-C)$ interaction with the dead body; (D) interaction with the vegetation; (E) looking at the carcass; (F, G) directing trunk towards carcass; $(\mathrm{H})$ interaction with other elephant. 
Table 2.

Number of visits and duration of visits per age class.

\begin{tabular}{|c|c|c|c|c|c|c|c|c|c|c|}
\hline & & $\begin{array}{c}1 \mathrm{st} \\
\text { visit }\end{array}$ & $\begin{array}{l}\text { 2nd } \\
\text { visit }\end{array}$ & $\begin{array}{c}\text { 3rd } \\
\text { visit }\end{array}$ & $\begin{array}{l}\text { 4th } \\
\text { visit }\end{array}$ & $\begin{array}{l}5 \text { th } \\
\text { visit }\end{array}$ & $\begin{array}{c}\text { 6th } \\
\text { visit }\end{array}$ & $\begin{array}{l}\text { 7th } \\
\text { visit }\end{array}$ & $\begin{array}{l}\text { 8th } \\
\text { visit }\end{array}$ & $\begin{array}{l}\text { 9th } \\
\text { visit }\end{array}$ \\
\hline \multirow[t]{4}{*}{ Af } & $N$ & 14 & 10 & 5 & 2 & 2 & 2 & 2 & 1 & 1 \\
\hline & Duration (min) & & & & & & & & & \\
\hline & Median & 2.5 & 3.5 & 6 & 3 & 2 & 10 & 4 & 13 & 2 \\
\hline & Range & $2-25$ & $2-9$ & $2-21$ & $2-4$ & - & $7-13$ & $2-6$ & - & - \\
\hline \multirow[t]{4}{*}{$\mathrm{Am}$} & $N$ & 9 & 9 & 7 & 3 & 2 & 2 & 2 & 1 & - \\
\hline & Duration (min) & & & & & & & & & \\
\hline & Median & 7 & 14 & 9 & 3 & 4 & 12.5 & 3 & 2 & - \\
\hline & Range & $2-26$ & $2-58$ & $3-39$ & $3-47$ & $3-5$ & $9-16$ & $2-4$ & - & - \\
\hline \multirow[t]{4}{*}{ Yam } & $N$ & 8 & 4 & 2 & 2 & 2 & 2 & 1 & - & - \\
\hline & Duration (min) & & & & & & & & & \\
\hline & Median & 9.5 & 2 & 54.5 & 11.5 & 2 & 15 & 3 & - & - \\
\hline & Range & $2-24$ & $2-44$ & $7-102$ & $9-14$ & - & $4-26$ & - & - & - \\
\hline \multirow[t]{4}{*}{ Saf } & $N$ & 7 & 2 & - & - & - & - & - & - & - \\
\hline & Duration (min) & & & & & & & & & \\
\hline & Median & 1 & 3 & - & - & - & - & - & - & - \\
\hline & Range & $1-6$ & - & - & - & - & - & - & - & - \\
\hline \multirow[t]{4}{*}{ Sam } & $N$ & 9 & 5 & - & - & - & - & - & - & - \\
\hline & Duration (min) & & & & & & & & & \\
\hline & Median & 4 & 5 & - & - & - & - & - & - & - \\
\hline & Range & $1-12$ & $1-25$ & - & - & - & - & - & - & - \\
\hline \multirow[t]{4}{*}{ Juv } & $N$ & 3 & 2 & 2 & 1 & 1 & & & & \\
\hline & Duration (min) & & & & & & & & & \\
\hline & Median & 1 & 1 & 1 & 3 & 1 & - & - & - & - \\
\hline & Range & $1-3$ & - & - & - & - & - & - & - & - \\
\hline \multirow[t]{4}{*}{ Inf } & $N$ & 9 & 4 & - & - & - & - & - & - & - \\
\hline & Duration (min) & & & & & & & & & \\
\hline & Median & 1 & 1.5 & - & - & - & - & - & - & - \\
\hline & Range & $1-10$ & $1-3$ & - & - & - & - & - & - & - \\
\hline
\end{tabular}

Abbreviations encode age classes (Af, adult females; Am, adult males; Yam, young adult males; Saf, subadult females; Sam, subadult males; Juv, juveniles; Inf, infants).

2019). Our findings additionally suggest sexually dimorphic responses, with females apparently being explorative while rarely physically interacting with the carcass or the surrounding vegetation. In contrast, males tend to stay longer and regularly interact with the carcass, vegetation, and each other physically, which suggests excitement around the carcass. Interaction with the vegetation was most likely not feeding related, as the corresponding se- 
ries of photographs never showed that plant parts were put into the mouth. This suggests that interactions with vegetation represent displacement behaviour, which is often provoked by social stress (e.g. in humans and nonhuman primates; Troisi, 2002). Similarly, displacement behaviour such as throwing dust on oneself or manipulating vegetation without eating it has been reported in savannah elephants to be mainly performed by lowerranking individuals during conflict situations around scarce resources or an object of interest (Poole \& Granli, 2011).

For forest elephants, Hawley et al. (2017) previously reported five visits within 65 days after the natural death of an adult female conspecific and three of these visits were made by females with their offspring. When controlling for time, our observations show more individuals that made considerably more visits. Furthermore, females in this study avoided bringing their offspring in close carcass proximity during the first three months. It seems that females performed some kind of risk management by consolidating two competing interests, namely to investigate the body and bones of a dead conspecific, while avoiding the risk that visits might pose to their dependent offspring. A similar phenomenon was observed in chimpanzees, where infants were prevented from approaching a dead female after a successful predator attack (Boesch, 2012). The risk anticipated by female elephants could be either directly linked to the carcass, or to male presence and competition over access to the carcass (Merte et al., 2009). The notion that females might avoid males is promoted by a sex-specific use of different water ponds in the near-by Baï and observations of females with dependent offspring, who usually move away from approaching males (Mbeli Baï Study, unpublished data).

Strikingly, we also observed high inter-individual behavioural differences in adult females and adult males. According to the "social information gathering hypothesis", individuals investigate dead conspecifics to keep track of recent social changes (e.g. dominance hierarchies, mating opportunities, territorial changes, or resource competition), and to appropriately adjust their behavioural responses during social interactions. Repeated visits made by adults and young adult males challenges the exclusiveness of the latter to explain interest in dead individuals. As observed in chimpanzees, previous encounters, relationship quality, and emotional state might additionally explain individual responses (Hosaka et al., 2000; Anderson et al., 2010). 
Unfortunately, we have no specific knowledge about the previous social relationships of the deceased male with the individuals that visited his carcass.

The delay in visits to the carcass for the first eight days after death, and the leaving behind of infants during visits is in contrast to several observations of savannah elephants, who usually visit deceased conspecifics immediately after death, with their infants (Douglas-Hamilton et al., 2006; Merte et al., 2009). Although we lack data on elephant presence before death, the state of the trail suggested regular use. We consider it thus unlikely that elephant use of this trail stopped coincidentally for the eight days following the poaching event and assume that individuals were initially avoiding the immediate vicinity of the carcass. Bai visitations patterns support the latter with an immediate decline in visiting elephants after the poaching event (Mbeli Baï, unpublished data). Although more systematic investigation is needed, delayed visitation patterns might have been due to initial avoidance of human presence that has been inferred by either hearing the gunshot or by olfactory cues. Despite high levels of protection within the National Park, negative experience with humans is still likely given that forest elephants can travel far beyond Park boundaries (Blake, 2002), and poaching pressure is higher in the periphery (Maisels et al., 2013). More systematic studies may reveal what information exactly elephants infer from dead bodies, including the possibility of conspecific recognition by bones alone (McComb et al., 2005), and whether they are able to infer the cause of death. Comparative approaches to these topics including other species will be particularly suitable to phylogenetically track the evolution of thanatological traits.

\section{Acknowledgements}

We are grateful to the Ministère de l'Economie Forestière, the Agence Congolaise de la Faune et des Aires Protégées (ACFAP), and to the Institut en Recherche Forestière within the Ministère de la Recherche Scientifique et de l'Innovation Technologique for permission to work in the Nouabalé-Ndoki National Park (research permit no. 270). We thank Milou Groenenberg, who oversaw camera trap maintenance from September to November 2017. We are grateful to people of the Nouabale-Ndoki National Park Management Unit as well as the WCS Congo office for their support to the Mbeli Baï Study. Particular thanks go to the editor and two anonymous reviewers for their very valuable comments that clearly helped to improve previous 
versions of the manuscript. This work was supported by the US Fish and Wildlife Service (USFWS); the USAID Central Africa Forest Ecosystems Conservation Project (CARPE); the European Union ECOFAC program; the Fondation pour le Tri-National de la Sangha (FTNS); Columbus Zoo and Aquarium; Cincinnati Zoo and Botanical Garden; Woodland Park Zoo; Riverbanks Zoo and Garden; Dublin Zoo; Dutch Gorilla Foundation; and Köln Zoo.

\section{References}

Anderson, J.R. (2016). Comparative thanatology. — Curr. Biol. 26: 553-556.

Anderson, J.R., Gillies, A. \& Lock, L.C. (2010). Pan thanatology. — Curr. Biol. 20: 349-351.

Bearzi, G., Kerem, D., Furey, N.B., Pitman, R.L., Rendell, L. \& Reeves, R.R. (2018). Whale and dolphin behavioural responses to dead conspecifics. - Zoology 128: 1-15.

Bercovitch, F.B. (2019). A comparative perspective on the evolution of mammalian reactions to dead conspecifics. — Primates 61: 21-28. DOI:10.1007/s10329-019-00722-3.

Blake, S. (2002). The ecology of forest elephant distribution and its implications for conservation. - Dissertation, University of Edinburgh, Edinburgh.

Boesch, C. (2012). Wild cultures: a comparison between chimpanzee and human cultures. Cambridge University Press, Cambridge.

Breuer, T. \& Fishlock, V.L. (2015). Studying forest elephants. — Neuer Kunstverlag/Neuer Sportverlag, Waiblingen.

Chiyo, P.I., Archie, E.A., Hollister-Smith, J.A., Lee, P.C., Poole, J.H., Moss, C.J. \& Alberts, S.C. (2011). Association patterns of African elephants in all-male groups: the role of age and genetic relatedness. - Anim. Behav. 81: 1093-1099.

Douglas-Hamilton, I., Bhalla, S., Wittemyer, G. \& Vollrath, F. (2006). Behavioural reactions of elephants towards a dying and deceased matriarch. - Appl. Anim. Behav. Sci. 100: 87-102.

Fishlock, V.L., Breuer, T. \& Lee, P.C. (2008). Quantifying forest elephant social structure in Central African bai environments. - Pachyderm 44: 17-26.

Fishlock, V.L. \& Lee, P.C. (2013). Forest elephants: fission-fusion and social arenas. Anim. Behav. 85: 357-363.

Fishlock, V.L. (2010). Bai use in forest elephants (Loxodonta africana cyclotis): ecology, sociality \& risk. - Dissertation, University of Stirling, Stirling.

Foley, C.A.H. (2002). The effects of poaching on elephant social systems. - Dissertation, University of Princeton, Princeton, NJ.

Gessner, J., Buchwald, R. \& Wittemyer, G. (2013). Assessing species occurrence and speciesspecific use patterns of bais (forest clearings) in Central Africa with camera traps. - Afr. J. Ecol.: 59-68.

Goldenberg, S.Z. \& Wittemyer, G. (2019). Elephant behavior toward the dead: a review and insights from field observations. - Primates 61: 119-128. 
Hawley, C.R., Beirne, C., Meier, A. \& Poulsen, J.R. (2017). Conspecific investigation of a deceased forest elephant (Loxodonta cyclotis). — Pachyderm 59: 97-100.

Hosaka, K., Matsumoto-Oda, A., Huffman, M. \& Kawanaka, K. (2000). Reactions to dead bodies of conspecifics by wild chimpanzees in the Mahale mountains, Tanzania. — Primate Res. 16: 1-15. DOI:10.2354/psj.16.1.

Huntington, R. \& Metcalf, P. (1979). Celebrations of death: the anthropology of mortuary ritual. - Cambridge University Press, Cambridge.

Klaus, G. (1998). Natural licks and geophagy (soil ingestion) by large mammal species in the rain forest of the Central African Republic. - Dissertation, University Zurich, Zurich.

Maisels, F., Strindberg, S., Blake, S., Wittemyer, G., Hart, J., Williamson, E.A., Aba'a, R., Abitsi, G., Ambahe, R.D., Amsini, F. \& Bakabana, P.C. (2013). Devastating decline of forest elephants in Central Africa. — PLoS ONE 8: e59469.

McComb, K., Moss, C.J., Durant, S.M., Baker, L. \& Sayialel, S. (2001). Matriarchs as repositories of social knowledge in African elephants. - Science 292: 491-494.

McComb, K., Baker, L. \& Moss, C. (2005). African elephants show high levels of interest in the skulls and ivory of their own species. - Biol. Lett. 2: 26-28.

Merte, C.E., Gough, K.F. \& Schulte, B.A. (2009). Investigation of a fresh African elephant carcass by conspecifics. - Pachyderm 45: 124-126.

Poole, J.H. \& Granli, P. (2011). Signals, gestures, and behavior of African elephants. — In: The Amboseli elephants: a long-term perspective on a long-lived mammal (Moss, C.J., Croze, H. \& Lee, P.C., eds). University of Chicago Press, p. 109-124.

R Core Team (2019). R: a language and environment for statistical computing. — R Foundation for Statistical Computing, Vienna. Available online at https://www.R-project.org/.

Shimane, K. (2018). Social bonds with the dead: how funerals transformed in the twentieth and twenty-first centuries. — Philos. Trans. Roy. Soc. Lond. B: Biol. Sci. 373: 20170274.

Sienne, J.M., Buchwald, R. \& Wittemyer, G. (2014). Differentiation in mineral constituents in elephant selected versus unselected water and soil resources at Central African bais (forest clearings). — Eur. J. Wildlife Res. 60: 377-382.

Stewart, F.A., Piel, A.K. \& O’Malley, R.C. (2012). Responses of chimpanzees to a recently dead community member at Gombe National Park Tanzania. - Am. J. Primatol. 74: 1-7.

Troisi, A. (2002). Displacement activities as a behavioral measure of stress in nonhuman primates and human subjects. - Stress 5: 47-54.

Turkalo, A. \& Fay, J.M. (1995). Studying forest elephants by direct observation. — Pachyderm 20: 45-54.

Turkalo, A.K. \& Fay, J.M. (2001). Forest elephant behaviour and ecology: observation from the Dzanga saline. - In: African rain forest ecology and conservation (Webber, W., White, L.J.T., Vedder, A. \& Naughton-Treves, L., eds). Yale University, New Haven, CT, p. 207-213.

Turkalo, A.K. (2013). Estimating forest elephant age. - Afr. J. Ecol. 51: 501-505.

Wittemyer, G., Douglas-Hamilton, I. \& Getz, W.N. (2005). The socioecology of elephants: analysis of the processes creating multitiered social structures. - Anim. Behav. 69: 13571371. 